\title{
Anxiety, CTCAE 5.0
}

National Cancer Institute

\section{Source}

National Cancer Institute. Anxiety, CT CAE 5.0. NCI Thesaurus. Code C146778.

A disorder characterized by apprehension of danger and dread accompanied by restlessness, tension, tachycardia, and dyspnea unattached to a clearly identifiable stimulus. 